\title{
Estado y Sociedad en las relaciones internacionales contemporáneas: evolución y transformaciones
}

Leonardo Granato ${ }^{1}$

Nahuel Oddone ${ }^{2}$

\section{Resumen}

El presente artículo tiene por objeto identificar los ejes fundamentales de la evolución y las transformaciones experimentadas por el Estado y su organización jurídica y política a lo largo de la historia hasta la actualidad, dando cuenta de las principales características de la sociedad contemporánea.

Palabras clave: Estado. Sociedad. Evolución. Transformaciones. Relaciones Internacionales.

\section{Introducción}

El presente artículo tiene por objeto identificar los ejes fundamentales de la evolución y las transformaciones experimentadas por el Estado y su organización jurídica y política a lo largo de la historia hasta la actualidad, dando cuenta de sus principales características.

\footnotetext{
${ }^{1}$ Abogado por la Universidad de Belgrano (Argentina). Magíster en Derecho de la Integración Económica por la Universidad del Salvador (Argentina) en convenio con l'Université Paris 1 Panthéon Sorbonne (Francia). Profesor de la Universidad Abierta Interamericana (Argentina), de la Universidad Nacional de Tres de Febrero (Argentina) y de la Universidad Internacional de Andalucía (España). Contacto:granato.leonardo@gmail.com

${ }^{2}$ Licenciado en Relaciones Internacionales por la Universidad Nacional del Centro de la Provincia de Buenos Aires (Argentina). Magíster en Derecho de la Integración Económica por la Universidad del Salvador (Argentina) en convenio con l'Université Paris 1 Panthéon Sorbonne (Francia), y en Integración Económica Global y Regional por la Universidad Internacional de Andalucía (España). Profesor de la Universidad Abierta Interamericana (Argentina), de la Universidad Nacional de Tres de Febrero (Argentina), de la Universidad de Belgrano (Argentina), de la Universidad Internacional de Andalucía (España) y de la Università degli Studi di Parma (Italia). Contacto: oddone.nahuel@gmail.com
} 
El desarrollo y las transformaciones de las instituciones que integran el sistema de derecho acompañan a los cambios que experimenta la organización del Estado. El Estado, organizado jurídicamente, es un atributo de la unitas ordinis que permite el contrato social.

Con inspiración en las enseñanzas del reconocido jurista argentino Roberto Dromi, podemos decir entonces que los tiempos del Estado se corresponden con los tiempos del derecho, toda vez que la forma del Estado se identifica con el orden jurídico que lo legitima.

Una de las formas de analizar el mundo en que vivimos es a partir de la historia. La historia nos precede y se adelanta a cualquier consideración, la historia nos enseña por analogía y como tal corresponda a las fuerzas sociales del presente considerar cuales situaciones son comparables. En este orden de ideas, delimitaremos una serie de períodos históricos a partir de los cuales será posible identificar las diversas experiencias de construcción de la organización jurídica de la sociedad occidental.

A continuación abordaremos la organización jurídica de la sociedad occidental, las características de la sociedad contemporánea y el diseño de las nuevas instituciones contemporáneas para después poder extraer algunas reflexiones sobre el rol del Estado y la Sociedad en las relaciones internacionales contemporáneas.

\section{La organización jurídica de la sociedad occidental}

Previo al análisis de la etapa de la modernidad es preciso que hagamos una sucinta descripción de la premodernidad. En la premodernidad los modelos es- 
tatales prevalecientes fueron la ciudad-estado ${ }^{3}$ y el imperio. Por un lado, las ciudades-estado como Atenas, Esparta, Cartagena o la Roma republicana, pero también le Repubbliche Marinare 4 como Venecia, Génova, Pisa o Amalfi, importaron siempre una estrecha delimitación de la estructura del poder local y de las potestas públicas. Por su parte, el imperio llevó la implícita dominación de unas ciudades por otras, erigida en cabeza de una organización política que excedía el perímetro natural de la urbe ${ }^{5}$.

La etapa histórica de la modernidad transformó todos los estratos de la sociedad, en el amplio abanico de sus manifestaciones tanto culturales y científicas cuanto políticas y económicas. Este momento histórico que, vivió su apogeo desde el inicio del siglo XVI hasta mediados del siglo XX, fue acompañado por el ocaso del régimen feudal y el surgimiento de nuevas reconfiguraciones territoriales.

La trascendencia de la evolución experimentada en la Edad Moderna guarda directa relación con la formación de los primeros Estados y la concepción de la

${ }^{3}$ En el ámbito de la premodernidad, se puede recordar la clásica obra de Tucídides y su "guerra del Peloponeso", en la que los pueblos y las ciudades eran los protagonistas de las situaciones internacionales. TUCÍDIDES. Historia de la guerra del peloponeso. México D. F.: Porrúa, 1989. Según Oddone: "Con anterioridad a 1492 se entiende que asistíamos a lo que se ha denominado 'situaciones internacionales' en las que las autoridades locales tenían un rol muy importante por constituir 'Ciudades-Estado' durante la antigua Grecia, los Reinos de Taifas del Al Andalus como conjunto de 'Ciudades-Estado' o las Ligas de Ciudades como Liga Hanséatica o las Repubbliche Marinare durante el Medioevo”. ODDONE, Nahuel. La red de mercociudades: globalización, integración regional y desarrollo local. Valencia: Instituto de Iberoámerica y el Mediterráneo de la Universidad Politécnica de Valencia, 2008. p. 78-79.

${ }^{4}$ BENVENUTI, Gino. Le Repubbliche Marinare. Amalfi, Pisa, Genova, Venezia. Roma: Newton \& Compton Editori, 1989. FRUGONI, Arcenio. Le Repubbliche Marinare. Torino: ERI, 1958. GIANFALDONI, Paolo. Le Antiche Repubbliche Marinare. Le origini, la storia, le regate. Pisa: $\mathrm{CLD}, 2001$.

5 "Roma creó el sistema de las provincias (Pro-vincere o para-vencedores), las que fueron aumentando de manera proporcional a la extensión que iban adquiriendo las posesiones conquistadas por los legionarios romanos. Su gobierno fue encomendado originariamente a los Praetores y luego a los pro-cónsules, magistratura de reciente creación, con imperium y con un plazo de duración que fijaba el Senado en cada caso. También correspondió al Senado -mediante un senatus-consultum- establecer las líneas generales de gobierno que debía seguir el pro-cónsul y, fundamentalmente, el caudal impositivo que debía remitir anualmente a Roma”. HUBEÑÁK, Florencio. Formación de la cultura occidental. Buenos Aires: Ciudad Argentina, 1999. p. 126-127. 
soberanía ${ }^{6}$. En esta etapa aparece el denominado "Estado Moderno", llamado luego de la Revolución Francesa "Estado-Nación".

La Historia de las Relaciones Internacionales construye a partir de dos hechos históricos su asociación con la idea de "Estado". La Paz de Westfalia de 1648, tras la Guerra de los Treinta Años (1618-1648), sería la normalización de la idea de Estado Moderno, en tanto que la ya mencionada Revolución Francesa de 1789, sumaría a ésta concepción la idea de "Nación"; determinando así la actual concepción sistémica de Estado-Nación.

Como destacara Sergio Fabbrini:

Sobre el hecho que los Estados-Nación se hayan consustanciado territorialmente no puede haber duda. Ha sido su capacidad de controlar un territorio preciso, entre el siglo XIV y el siglo XVII, la que consintió al Estado de luchar contra sus 'rivales': las ligas y las Ciudades-Estado ${ }^{7}$.

Sumando la propuesta de Fabbrini con la del prestigioso historiador Charles Tilly $(1975,1992)$, podríamos decir que la única forma que tenía el EstadoNación para poder sobrevivir era "exportando" esa misma forma de organización política europea al resto del mundo vis-à-vis se favorecía la formación de un sis-

\footnotetext{
${ }^{6}$ Niccolò Macchiavelli desarrolló en 1513 una teoría política del Estado que plasmó en la redacción del "Il Principe". En esta clásica obra entendió la estructura del Estado sobre la base del poder, sustentando la realidad política sobre la base de esta esfera autónoma, independiente y dirigida por su propia razón particular: la razón de Estado. En la misma época, Jean Bodin elaboró el concepto de soberanía en "Los Seis Libros de la República". Según este autor: "La soberanía es el poder absoluto y perpetuo de una república [...]. Es preciso ahora poder aclarar lo que significa poder soberano. Digo que este poder es perpetuo, puesto que puede ocurrir que se conceda poder absoluto a uno o a varios por tiempo determinado, los cuales, una vez transcurrido éste, no son más que súbditos. Por tanto, no puede llamárseles príncipes soberanos cuando ostentan el poder, ya que sólo son sus custodios o depositarios, hasta que place al pueblo o al príncipe revocarlos. Es éste quien permanece siempre en posesión del poder [...]. La soberanía no es limitada, ni en poder, ni en responsabilidad, ni en tiempo". BODIN, Jean. Los Seis Libros de la República. Madrid: Tecnos, 1997. p. 47-48.

${ }^{7}$ FABBRINI, Sergio. Il processo d'integrazione europea: quali insegnamenti per le altre esperienze di aggregazione regionale. En: CONFERENCIA EL PROCESO DE INTEGRACIÓN EUROPEO: ENSEÑANZAS PARA OTRAS EXPERIENCIAS DE INTEGRACIÓN REGIONAL. Ponencia preparada para la conferencia... Organizada por la Universidad Abierta Interamericana y el Centro Argentino de Estudios Internacionales. Buenos Aires, 2007. p. 15. Véase también: SPRUYT, Hendrix. The sovereign state and its competitors. Princeton: Princeton University Press, 1994.
} 
tema de acumulación capitalista de alcance mundial en la propuesta de Giovanni Arrighi (1999) ${ }^{8}$.

Con el Estado-Nación y su potestad soberana se establecieron las bases del orden constitucional del siglo XVIII, instaurando el denominado "Estado de Derecho" sobre el principio de sumisión a la ley, como república o como monarquía constitucional.

Asimismo, la independencia de los Estados Unidos (1776) y la Revolución Francesa (1789) permitieron la consagración positiva de uno de los mayores aportes en materia política del siglo XVIII: la teoría de la división de las funciones del poder, formulada años antes por el Barón de Montesquieu. El Estado Moderno fue dotado de una de las características fundamentales que lo identifican en la actualidad y que han permitido su supervivencia como organización social: el reparto del poder entre los órganos del Estado sobre la base de la distinción de la naturaleza de las funciones por ellos ejercidas.

Sin embargo, la sola distribución de las funciones del poder no se presenta como el único requisito para la constitución de un Estado Moderno; es necesario y vital el reconocimiento y respeto de los derechos del hombre, tal como dejara de manifiesto Alexis de Tocqueville en su obra "La Democracia en América".

${ }^{8}$ También podríamos relacionar esta concepción con la posterior propuesta de la constitución de una Economía mundo capitalista teorizada por el sociólogo francés Immanuel Wallerstein. El autor Wallerstein acuñó el concepto de economía-mundo. Este identifica al sistema mundo capitalista como una economía mundo capitalista, que abarca un único espacio social que se extiende progresivamente. Su dinámica de desarrollo es un proceso de autoinclusión. En una primera etapa, el sistema capitalista funcionó en el reducido campo de la economía, pero para transformarse en un sistema social es que debía dar origen a la formación de un sistema de Estados debido a que estos podían asegurar la división internacional del trabajo; pero al mismo tiempo la existencia de ésta pluralidad de unidades político-estatales al interior de la economía mundo capitalista impedía la transformación del sistema en un Imperio-Mundo. WALLERSTEIN, Immanuel. El moderno sistema mundial: la agricultura capitalista y los orígenes de la economía mundo europea en el siglo XVI. México: Siglo XXI, 1991. La propuesta del 'sistemamundo’ define la economía global como una división continúa del trabajo entre los Estados. Recientemente, la socióloga Saskia Sassen ha criticado la propuesta wallerstoniana pues "hoy en día la diferenciación entre el centro y la periferia no pasa tanto por la diferenciación entre los procesos de producción o las posiciones en los procesos de producción, sino más bien por una diferenciación funcional que atraviesa las espacialidades predeterminadas en el trabajo de Wallerstein. Cuando define la economía mundial básicamente como una red de relaciones entre Estados territoriales, Wallerstein anula la posibilidad de conceptualizar la globalización como algo más que la mera expansión de la economía global para incorporar nuevos territorios. En su análisis, se vuelve invisible la posibilidad de una reconstrucción de la espacialidad del capitalismo global". SASSEN, Saskia. Una sociología de la globalización. Buenos Aires: Katz, 2007. p. 74. 
Si bien los aportes hasta aquí mencionados constituirán la base teórica de aproximación y construcción del concepto de Estado Moderno, será Max Weber quien desarrollará la conceptualización del Estado en su acepción occidental. El Estado es aquel que recepta para sí el monopolio de la fuerza física legítima, la que se ejerce sobre un territorio específico y una población dada.

En este sentido, podemos sostener que:

El estudio de las relaciones internacionales se ocupa sobre todo de analizar y de explicar los tratos entre las comunidades políticas organizadas dentro de un territorio, es decir, entre los Estados. [...] debe tenerse en consideración los vínculos establecidos entre los pueblos $\mathrm{y}$ entre los individuos [...]: el intercambio de productos y de servicios, las comunicaciones de ideas, el juego de las influencias recíprocas [...], las manifestaciones de simpatía o antipatía. Pero reconoce que rara vez estas relaciones pueden disociarse de las que se han establecido entre los Estados [...]. Reguladas por los Estados, se convierten en un elemento de negociación o de conflictos entre los gobiernos. Por tanto, es la acción de los Estados la que se encuentra en el centro de las relaciones internacionales. ${ }^{9}$

En palabras de Krippendorff:

Hablar de 'política internacional' significa hablar de Estado. Parece una verdad sobreentendida que el Estado constituye el verdadero objeto de las relaciones internacionales, su 'actor' y 'autor de las acciones'10.

La posmodernidad sería característica del siglo XX. El tercer escalón histórico puede ubicase finalizada la Segunda Guerra Mundial, conjuntamente con la creación de los organismos internacionales políticos, económico-financieros y administrativos que sirvieron para resguardar la paz y seguridad internacionales en la época de posguerra ${ }^{11}$.

9 RENOUVIN, Pierre; DUROSELLE, Jean Baptiste. Introducción a la historia de las relaciones internacionales. México D. F.: Fondo de Cultura Económica, 2000. p. 9.

${ }^{10}$ KRIPPENDORFF, Ekkhart. Las relaciones internacionales como ciencia. México D. F.: Fondo de Cultura Económica, 1993. p. 65.

${ }^{11}$ No es casual que el reconocido jurista austríaco Hans Kelsen plasmara hacia el final de su vida, en 1944, sus enseñanzas filosóficas en aplicaciones pragmáticas, que buscaban crear un nuevo derecho internacional que garantizara el derecho a la paz. 
En este contento, según entiende Dromi:

El final de la modernidad implicó la posibilidad de cuestionar públicamente las tesis dominantes de la Ilustración. El pensamiento moderno se presenta en esta etapa como una ficción intelectual que se ha tornado inconsecuente, pues ha fallado en su paradigma fundante: la certeza racionalista y el progreso indefinido ${ }^{12}$.

A partir de este momento histórico surgieron importantes novedades como la cooperación internacional, que continuó creciendo a través del entendimiento, manifestado en pactos y acuerdos políticos como la creación de las Comunidades Europeas, que tuvo inicio en 1950.

En este orden de ideas, el Estado globalizado es un instrumento político de la posmodernidad caracterizada por las vacilaciones entre la coexistencia y el dominio internacional, como consecuencia del enfrentamiento entre la posición capitalista liderada por Estados Unidos y la comunista dirigida por la Unión de Repúblicas Socialistas Soviéticas, diferencias que frías o templadas obtuvieron su desenlace recién en la última década del siglo $\mathrm{XX}^{13}$.

El debilitamiento del Estado-Nación dio lugar pues a un Estado posmoderno signado por el proceso de la globalización. Así surgió la interpretación del "Estado globalizado", producto de la masificación de la producción y el comercio mundiales, y posteriormente vigorizado por el aparente triunfo del llamado "pensamiento único" tras la caída de los regímenes comunistas.

Vemos así la globalización con un componente eidético-cultural y dentro de éste connotaciones ideológicas. La globalización vista como ideología, tiene un marcado carácter a-histórico y se la identifica como la nueva herramienta para la colonización política y cultural que se impuso sobre los países en desarrollo ${ }^{14}$.

${ }^{12}$ DROMI, Roberto. El derecho público en la hipermodernidad. Madrid-México D. F.: Hispania libros y servicio de publicaciones de la facultad de derecho de la Universidad Complutense, 2005. p. 17.

${ }^{13}$ PEREIRA CASTAÑARES, Juan Carlos. Los orígenes de la guerra fría. Madrid: Arco, 1997. p. 11.

${ }^{14}$ BERNAL-MEZA, Raúl. Sistema mundial y MERCOSUR. Buenos Aires: Universidad Nacional del Centro de la Provincia de Buenos Aires: Nuevo Hacer-Grupo Editor Latinoamericano, 2000. p. 65. 
Dentro del carácter a-histórico de la globalización es que se ubica al pensamiento único. La visión fundamentalista e ideológica de la globalización ha producido un proceso de alienación cultural, en el cual las alternativas de pensamiento económico y de política pública se redujeron al llamado pensamiento único ${ }^{15}$.

Pensamiento único y globalismo se conjugan en la actual etapa de la mundialización como el complejo eidético-cultural que constituye a la globalización. Los principales acontecimientos que han determinado las características del mundo moderno tienen su origen en amplios y profundos procesos de análisis, evaluación y planificación cuyo ámbito podríamos decir, se encuentra fuera de lo que usualmente denominamos como de "dominio público".

El globalismo es visto según Pérez Serrano como:

El fiel continuador del que los ideólogos del autoproclamado Mundo Libre difundieron en los años de la Guerra Fría, como prolongación de la doctrina de la seguridad nacional. Todo lo que sucede en el mundo tiene, en mayor o menor medida, un efecto global y, por ende, es susceptible de ser interpretado como una amenaza para la seguridad de los $\operatorname{poderosos}^{16}$.

Tal como sostuviéramos:

En contraposición con la visión mundialista de la realidad internacional, la globalización refleja una ideología alineada eminentemente con una cosmovisión anglosajona, o más precisamente, angloestadounidense del mundo. Sitúa el eje determinante del devenir social en lo económico-financiero, o sea, en el poder privado al cual pretende subordinar toda estructura y accionar político. La globalización exige el control 'sobre' todos los Estados del mundo, es el poder privado controlando y actuando 'por encima' del poder público $^{17}$.

${ }^{15}$ BERNAL-MEZA, Raúl. Argentina: la crisis del desarrollo y de su inserción internacional. São Paulo: Fundación Konrad Adenauer Stiftung, 2001. p. 39. (Documentos de Análisis e Informaciones, n. 1).

${ }^{16}$ PÉREZ SERRANO, Julio. Globalización y pensamiento único. En: ENCUENTRO DE FIN DE SIGLO. UTOPÍAS, REALIDADES Y PROYECTOS. Ponencia presentada en el encuentro... Salta: Universidad Nacional de Salta, 2001. p. 7.

${ }^{17}$ ODDONE, Nahuel; GRANATO, Leonardo. La globalización como proceso e ideología: las desigualdades se acrecientan. Revista Debates Latinoamericanos, Buenos Aires, a. 2, n. 3, p. 55, 2004. 
En la actual etapa el globalismo se ha revestido de nuevos argumentos y ha pasado a convertirse en el ingrediente más sólido del llamado pensamiento único, al que no sólo dota de una poderosa lógica interna, sino también del vocabulario específico capaz de manipular eficazmente las nuevas realidades de la globalización ${ }^{18}$.

En un anterior artículo entendíamos que:

En este contexto, el eje del globalismo lo conforman las estructuras económicas privadas, por lo que presupone el debilitamiento, disolución y eventual desaparición -agregan otros- del Estado-Nación soberano, de 'todos' los EstadosNación soberanos. Y esto a la vez responde al momento actual en el que impera la concentración de poder ${ }^{19}$.

El globalismo es así componente esencial del pensamiento único. Las alianzas políticas fueron seguidas por otras de carácter económico y juntas conformaron nuevos órdenes de tipo multilateral y regional.

Las implicancias sistémicas a las que hacemos mención, se analizan desde la perspectiva sostenida por el reconocido autor francés Duroselle. El estudio de las relaciones internacionales no es posible si no se analiza cada situación, cada mecanismo, desde los ángulos de la 'finalidad' -entendida en el sentido que quien dispone de un poder se propone fines e intenta llevarlos a cabo- y de la 'causalidad' -las colectividades humanas ejercen confusamente fuerzas cuya resultante modifica los acontecimientos- ${ }^{20}$.

Es por ello que dentro de las relaciones internacionales, existen acontecimientos históricos que alcanzan significados simbólicos y connotaciones sociológicas fundantes, podemos decir, con implicancias históricas concretas. Por ejemplo, los atentados del 11-S de 2001 a las torres gemelas del World Trade Center y del 11-M de 2004 a la estación Atocha en Madrid son sucesos que comportan estas características.

${ }^{18}$ PÉREZ SERRANO, Julio. Globalización y pensamiento único. En: ENCUENTRO DE FIN DE SIGLO. UTOPÍAS, REALIDADES Y PROYECTOS. Ponencia presentada en el encuentro... Salta: Universidad Nacional de Salta, 2001. p. 7.

${ }^{19}$ ODDONE, Nahuel; GRANATO, Leonardo. La globalización como proceso e ideología: las desigualdades se acrecientan. Revista Debates Latinoamericanos, Buenos Aires, a. 2, n. 3, p. 56, 2004.

${ }^{20}$ DUROSELLE, Jean Baptiste. Tout empire périra: théorie des relationsi internationales. Paris: Aeman Collin, 1992. 
De esta manera, la cuarta etapa de la evolución del Estado asiste a un aumento del diálogo internacional multi-nivel materialización de las estructuras sistémicas signadas por la interdependencia compleja ${ }^{21}$; la pretendida construcción de una agenda política que se encauce de manera grupal bajo el decadente liderazgo estadounidense.

La problematicidad de nuevos flagelos internacionales y el múltiple surgimiento de problemas intermésticos ponen a todos los Estados y los hombres del sistema internacional frente a la necesidad de construir nuevas escalas de governance desde las cuales poder dar respuestas conjuntas a problemas comunes.

En las condiciones actuales, pareciera ser que poco sirve a la Nación sus vinculaciones con el Estado. Para algunos autores es una cuestión de proporcionalidad. El Estado es un instrumento para dar respuesta a las necesidades de una Nación. Pero la cuestión es que la Nación, y el Estado, su instrumento, se hacen demasiado pequeños para dar respuesta a algunos problemas, y demasiado grandes para arreglar los pequeños problemas locales. Esta cuestión Nación-Estado, entraría dentro de lo que Anthony Giddens ha denominado “instituciones conchillas", instituciones que se han vuelto inadecuadas para las tareas que están llamadas a cumplir. Externamente se las percibe como iguales pero internamente se encuentran en un proceso de cambio. A este tipo de instituciones Ulrich Beck las llama “instituciones zoombies”.

${ }_{21}$ "El concepto de interdependencia compleja se relaciona con el surgimiento de un orden multipolar en el cual la hegemonía deja lugar a la supremacía, con una agenda internacional sin jerarquías, con el surgimiento de canales múltiples de reracionamiento que pueden ser interestatales, transgubernamentales o transnacionales; y con la devaluación creciente de la fuerza militar y el aumento de la importancia económica en el sistema. En este sentido, la interdependencia compleja pretende presentarse como un sustituto funcional al mantenimiento del orden internacional configurado en la Posguerra Fría y la continuidad de la supremacía norteamericana mediante el sostenimiento de los regímenes internacionales creados bajo su período de hegemonía: Organización de Naciones Unidas (ONU), Acuerdo General de Aranceles y Tarifas (según sus siglas en inglés GATT), la Organización de Cooperación y Desarrollo Económico (OCDE), entre otros". GRANATO, Leonardo; ODDONE, Nahuel. El sistema internacional y la integración económica regional. En: DURÁN SÁENZ, Susana, GRANATO, Leonardo; ODDONE, Nahuel (Comp.). Regionalismo y globalización: procesos de integración comparados. Buenos Aires: Universidad Abierta Interamericana, 2008. p. 18. 
Francisco Jarauta nos cuenta que:

Ha sido Ulrich Beck quien ha planteado lúcidamente la necesidad de leer en contextos globales aquellos acontecimientos que escapan a la lógica y previsión de los modelos convencionales de la lectura histórica. Se trata de una lógica borrosa e imprecisa en la que se condensan las tensiones generadas a lo largo del tiempo. Los riesgos que anotaba Beck como intrínsecos a la historia moderna y globalizada no eran independientes de los que analizara Zygmunt Bauman, en su 'Globalization, the Human Consecuences'. Se trataba así de articular los diferentes niveles del proceso particularmente en relación a los efectos y consecuencias que de ellos derivan ${ }^{22}$.

\section{La sociedad contemporánea}

Frente a los peligros actuales que constituyen una suerte de "rechazos" explícitos de la lógica moderna, la "Hipermodernidad” en palabras de Gilles Lipovetzky $^{23}$ o la "Modernidad Liquida" en palabras de Zygmunt Bauman ${ }^{24}$, surgen como una "nueva modernidad", potenciada y superadora, en la que se procura renovar la defensa de los derechos del hombre, en convivencia con otros fenómenos tales como los mercados ampliados más allá de las fronteras bajo la lógica de la liberalización económica y la tecnociencia generadora de la tecnocracia; y que, como señalan algunos pensadores, es en la búsqueda y en el hallazgo de certezas, que se vuelven a marcar los límites y las exigencias, deseando "compartir" la soberanía, rescatando el poder del Estado en la regulación y en el control, e intentando "solidarizar" la economía, fiscalizar los mercados e incorporar las organizaciones sociales en la instancia y ejercicio de la responsabilidad pública, tanto para la gestión como para fiscalización de acciones y conductas de interés público general.

El avance y desarrollo de la civilización occidental, que algunos autores han denominado "occidentalización", se ha caracterizado, desde el advenimiento de la Edad Moderna, por la expansión de las fronteras científicas y culturales, sociales, económicas y geográficas, en un proceso paulatino y constante de extensión global.

\footnotetext{
${ }^{22}$ JARAUTA, Francisco. Presentación. Foro de la mundialización: después del 11 de septiembre. Murcia: Fundación CajaMurcia, 2003. p. 8.

${ }^{23}$ LIPOVETZKY, Gilles-Charles-Sébastien. Les temps hypermodernes. Paris: Grasset, 2004.

${ }^{24}$ BAUMAN, Zygmunt. Modernidad líquida. Buenos Aires: Fondo de Cultura Económica, 2006.
} 
La dinámica inherente a este desarrollo civilizacional, así como su vocación universalizadora, han tenido por consecuencia la aparición de un nuevo fenómeno ya mencionado y conocido como globalización.

Como ya hemos adelantado desde hace ya algunos años, el sentido de las palabras mundialización y globalización se han hecho más precisos. Mientras que el término mundialización adquiere una connotación esencialmente económica, el término globalización posee una connotación tanto económica como políticoideológica. La globalización no constituye una nueva civilización planetaria sino que designa la multiplicación de los intercambios y la mejora de las comunicaciones internacionales que estimulan a hablar de una integración de los agentes económicos en el nivel mundial.

La globalización no es un proceso distinto o autónomo de la historia social y económica del sistema mundial; siendo el eslabón de un largo proceso que se inicia con la internacionalización y que continúa con la transnacionalización de la economía al que se le suma la fusión entre lo real y lo simbólico que genera la apariencia de un mundo sin fronteras y configura un orden global específico y por tanto con uno contenido ideológico determinado.

Las distancias acortadas por la globalización no son sólo geográficas. También ha ocurrido la democratización y la difusión parcial del conocimiento que ha caracterizado a la segunda mitad del siglo pasado, configurando así un mundo físicamente unido pero a la vez que culturalmente estratificado con presencia de las denominadas brechas social, tecnológica, científica o cultural, entre otras. La difusión y democratización del conocimiento ha sido claramente parcial en un mundo donde los derechos de autor, la propiedad intelectual y las patentes industriales y farmacéuticas se han convertido en verdaderos ejes de discusión en las mesas de negociación global y de litigio entre los Estados.

Existe además una reconversión de la relación entre lo local y lo global. La sociedad se articula hoy sobre la base de la convivencia de dos aldeas; la global y la local. Es la realización de aquella idea de "pensar globalmente y actuar localmente". Los hombres poseen ahora más espacios comunes $y$, aparentemente, menos fronteras. Ello se parece verificarse en la conciencia de la sociedad civil, en la mutación del concepto de soberanía, en el dominio de la sociedad del conocimiento, en la 
propiedad del saber, y en la instalación de dinámicas redes tecnológicas de comunicación e información sin fronteras, que generan un hábitat de sobre-información, transparencia e interconexión generando una suerte de dinámica que algunos autores han identificado como "glocal".

Como han sostenido Robertson y White:

Actualmente la forma de la globalización se remodela reflexivamente [...] en manera tal de acentuar los proyectos de glocalización como característica constitutiva de la globalización contemporánea ${ }^{25}$.

En la organización social "hipermoderna", donde el hombre es elevado a la categoría de "ciudadano del mundo", las distancias se acortan y las capacidades se prolongan. La vida es local y global a la vez. Como hemos denominado en otro trabajo han surgido las obligaciones glocales ${ }^{26}$. En el contexto actual de glocalización, los procesos de democratización política y de descentralización del Estado, ambos necesariamente capitalistas, revalorizan el papel de las autoridades y gobiernos locales.

La interconexión terminó con mapas y distancias; el acceso a la tecnología ha hecho del mundo común un hábitat entre espejos donde los hombres comparten, si bien en distinto grado, las mismas aspiraciones.

El término "topopoligamia" ha sido acuñado por el sociólogo Ulrich Beck. Un mundo topopoligámico es aquel en el que los ciudadanos reconocen su "pertenencia" a varios lugares distintos a la vez, es estar casado con muchos sitios al mismo tiempo, lo que lleva a la globalización de la propia vida o biografía. Como sinónimos de topopoligamia, encontramos a la "multilocalidad" o la "politopicidad".

Siguiendo a Beck entendemos que:

La multilocalidad o politipicidad, la transnacionalidad de la biografía y la globalización de la propia vida; proporcionan un motivo ulterior para el socavamiento de la soberanía del Estado nacional [...]; se disuelve así, la interdependencia

${ }^{25}$ ROBERTSON, Ronald; WHITE, Kathleen. La glocalizzazione rivisitata ed elaborata. En: SEDDA, Franciscu. (Comp.). Glocal: sul presente a venire. Roma: Luca Sosella, 2004. p. 32.

${ }^{26}$ Sobre este punto, véase la introducción y tercera parte del libro: ODDONE, Nahuel. La red de mercociudades: globalización, integración regional y desarrollo local. Valencia: Instituto de Iberoámerica y el Mediterráneo de la Universidad Politécnica de Valencia, 2008. p. 78-79. 
entre lugar y comunidad (o sociedad). El acto de cambiar de y de elegir lugar es el padrino de la glocalización de las biografías" 27 .

La vinculación global-local se constituye a partir de una tensión vivencial: la desterritorialización se da en paralelo a la reinvención del territorio como requisito funcional y como principio político del nuevo orden glocal.

Como nos recuerda Bauman:

Parece haber una afinidad íntima, un condicionamiento mutuo y un fortalecimiento recíproco entre la 'globalización' de todos los aspectos de la economía y el renovado énfasis sobre el 'principio territorial'28.

La aldea global y la aldea local se dan la mano en una relación de abstracción y territorialidad. La aldea global de la abstracción se materializa en la aldea local de la territorialización.

Desde la perspectiva de Dromi:

La aldea global es un espacio abstracto, con un poder cultural dominante que provee de definiciones y contenidos a esta gran red de interconexión. La aldea local es su dimensión concreta y personalizada, con una realización urbana y rural adyacente, que integra la heterogeneidad social a la tecnología y al conocimiento de la red global; es la que devuelve -de algún modo- certeza, confianza, desarrollo y seguridades al hombre, una vez que se ha sumado a la red de los servicios esenciales y a los rumbos de la integración de la economía. La agenda del presente parecería exigir la construcción de nuevos mapas de interconexión y el conocimiento de la nueva geografía científica y de los nuevos mercados y espacios de la cultura del trabajo ${ }^{29}$.

La sociedad contemporánea vive en la "vacilación" de las nuevas definiciones del Estado y de la formulación de nuevas certezas. En este sentido, el desafío para la ciencia política, el derecho y la economía es categórico a los efectos de

${ }^{27}$ BECK, Ulrich. ¿Qué es la globalización? falacias del globalismo, respuestas de la globalización. Barcelona: Paidós, 1997. p. 111.

${ }^{28}$ BAUMAN, Zygmunt. La globalización: consecuencias humanas. Buenos Aires: Fondo de Cultura Económica, 2006. p. 91.

${ }^{29}$ DROMI, Roberto. El derecho público en la hipermodernidad. Madrid-México D. F.: Hispania libros y servicio de publicaciones de la facultad de derecho de la Universidad Complutense, 2005. p.32. 
crear nuevos marcos conceptuales de contención para la vacilación humana. Los tiempos de la política, el derecho y la economía deben acompañar y contener los tiempos de la humanidad.

\section{El diseño de las nuevas instituciones jurídicas contemporáneas}

La historicidad es un elemento de suma importancia en toda construcción institucional. La hipermodernidad o modernidad líquida tan sólo reclaman una nueva organización y una renovada redistribución político-económica que permitan la construcción de eficientes instancias de convivencia social por las cuales se reedifiquen los cánones y los códigos que informan y protegen a la sociedad.

La relación entre los individuos y la sociedad se traduce en el plano político en la relación entre los ciudadanos y el Estado ${ }^{30}$. Una estructura política estatal dada es fiel reflejo de la sociedad y, por lo general, se encuentra dividida entre los que tienen poder y mandan y los que no lo tienen y por tanto, obedecen. Entre unos y otros late la lógica relacional y general del poder de los que gobiernan -y que poseen una autoridad tal con mandato expreso- y el de los que obedecen -bajo su condición de libertad-.

No hay libertad sin Estado. Tal como manifestara Dromi:

La libertad y la autoridad se presuponen; no existe verdadera libertad sin autoridad, tal como lo demuestran las distintas situaciones de anarquía que se han producido a lo largo de la historia; ni es autoridad real la que prescinde de la libertad de los gobernados, sino un ejercicio despótico del poder, sin más legitimación que la propia fuerza ${ }^{31}$.

\footnotetext{
30 "La quintaesencia de la democracia consiste en que el pueblo participa en la formación de la voluntad política de la comunidad. Los elementos personales del pueblo son los ciudadanos. [...] En la democracia moderna la regla debe ser que un integrante es ciudadano [...]. Siendo, pues, el número de ciudadanos siempre relativamente grande, surge el problema de la unificación de la voluntad. Este problema se resuelve o por medio de la votación o mediante el sorteo [...]. La democracia descansa en la igualdad de los ciudadanos [...]. Básicamente la igualdad democrática es la igualdad con respecto al destino común de los ciudadanos". GOLDSCHMIDT, Werner. El principio supremo de justicia. Buenos Aires: Editorial de la Universidad de Belgrano, 1984. p. 34.

${ }^{31}$ DROMI, Roberto. El derecho público en la hipermodernidad. Madrid-México D. F.: Hispania libros y servicio de publicaciones de la facultad de derecho de la Universidad Complutense, 2005. p.33.
} 
La propia existencia del Estado de Derecho requiere de un juego armónico entre autoridad y libertad dentro de una comunidad política. Sólo puede haber libertad real donde existe un ejercicio legítimo y justo de la autoridad; la que resulta desnaturalizada si el derecho no oficia de límite y contención del poder. La evolución político-jurídica ha permitido generar un consenso universal sobre derechos y competencias, libertades y prerrogativas que deben necesariamente armonizarse dentro del marco del orden jurídico constitucional, con base en una ley fundamental ${ }^{32}$.

La reformulación de la ecuación sintetizada en la relación "autoridad-libertad" ha tenido por consecuencia una renovación de las condiciones en que se vinculan los ciudadanos con el Estado a lo largo de los años. Los cambios en la relación se han visto manifestados en las potestades subjetivas y los derechos del hombre. Así las cosas, como consecuencia natural, el Estado debe dar respuesta a esta nueva realidad, satisfaciendo las crecientes demandas de una sociedad civil que se muestra cada vez más comprometida con la solidaridad y participación social.

La prudencia política, refrendada por la experiencia histórica, permite sostener que no existe mejor forma de defender la libertad que instaurar el derecho como "límite del poder"33.

Los derechos fundamentales derivan de la propia dignidad del ser humano, el cual es el destinatario principal de la protección estructurada desde el Estado. De la protección emana la igualdad esencial en tanto seres racionales que buscan acceder a la verdad.

La dignidad esencial del hombre junto con la protección de su vida, libertad y propiedad se traducen en la necesidad de un reconocimiento positivo de los derechos y garantías producto de las relaciones sociales establecidas, núcleo del

\footnotetext{
32 "La idea de que hay en todos los regímenes una ley especial, una ley suprema, una ley de leyes es una idea muy antigua. En cierta medida podríamos rastrear en la historia de las instituciones europeas y en el de otras civilizaciones este concepto. Hay, en algún momento, en todos los ordenamientos jurídicos una regla, una norma, una ley que es distinta a las otras y que en cierta forma se la considera vértice o culminación de esa pirámide de normas que supone el conjunto de reglas que rigen a una sociedad". COLOMER VIADEL, Antonio. Constitución, estado y democracia en el siglo XXI. Valencia: Editorial de la Universidad Politénica de Valencia, 2006. p. 43.

${ }^{33}$ DIEZ PICAZO, Luis María. Sistema de derechos fundamentales. Madrid: Thompson-Civitas, 2003. p. 27-28.
} 
constitucionalismo moderno. No se trata de derechos absolutos; pues todos los ordenamientos prevén sus propios límites, que deben resguardar una razonable relación con el contenido esencial de los derechos fundamentales.

Estos derechos fundamentales tienen preeminencia formal sobre las prerrogativas del Estado, por lo que deben ser organizados para garantizar su efectiva vigencia. Son derechos naturales, inalienables e imprescriptibles, piedra angular de toda axiología jurídica, de inexcusable referencia en la construcción constitucional de un Estado democrático y necesarios de adaptación en cada etapa de la historia ${ }^{34}$.

En cuanto las "generaciones" de dichos derechos fundamentales, Dromi nos recuerda que:

Los derechos fundamentales de primera generación, relativos a las libertades públicas y aparecidos en los albores del constitucionalismo formal, a finales de la Edad Moderna, y los de segunda generación o sociales, propios de la primera mitad del siglo XX, han cedido el protagonismo a los derechos que conciernen a la sociedad en su conjunto, que no tienen una titularidad individualizada sino que corresponden al colectivo humano, como los derechos que se refieren al medio ambiente, a las relaciones de consumo, al desarrollo sustentable o a la protección del acervo cultural e histórico. Estos derechos, denominados por la doctrina como de "tercera generación", requieren de herramientas procesales que posibiliten su tutela jurisdiccional expedita y eficiente. Por ello, la declamación constitucional de los derechos fundamentales debe hallarse acompañada de la previsión de las garantías que aseguren su efectiva vigencia $^{35}$.

Hoy en día, la mayoría de los textos constitucionales contienen el reconocimiento de derechos fundamentales tanto de un modo explícito cuanto implícito

\footnotetext{
${ }^{34}$ Como nos indica un autor: "ello se resume en la famosa fórmula del artículo 16 de la Declaración Universal de los Derechos del Hombre y del Ciudadano, aprobada al comienzo de la Revolución Francesa, en 1789, cuando nos dice que en una nación, en una sociedad en donde no estén reconocidos los derechos del hombre y establecida la división de poderes, carece de Constitución". COLOMER VIADEL, Antonio. Constitución, estado $y$ democracia en el siglo XXI. Valencia: Editorial de la Universidad Politénica de Valencia, 2006. p. 46.

${ }^{35}$ DROMI, Roberto. El derecho público en la hipermodernidad. Madrid-México D. F.: Hispania libros y servicio de publicaciones de la facultad de derecho de la Universidad Complutense, 2005. p. 36-37.
} 
incorporando los diferentes tratados internacionales de derechos humanos, lo que ha implicado una considerable expansión de los derechos fundamentales reconocidos y de sus garantías.

En este sentido y tal como manifestara el jurista argentino Sagüés:

$\mathrm{El}$ auge del derecho transnacional, presente en las nuevas constituciones con distintas variaciones; pero, en general, con un reconocimiento, en las constituciones nacionales, de las normas del derecho internacional [...]. Ello importa admitir, normalmente, la existencia de la jurisdicción y de la magistratura transnacional, por sobre las autoridades locales $^{36}$.

Los procesos de integración económica regional también han incidido en la conformación de un bloque de derechos fundamentales común a los Estados miembros en conjunción con la construcción y consolidación de un bloque de principios y cláusulas democráticas ${ }^{37}$. Los ciudadanos de los Estados que se incorporan a los nuevos espacios de solidaridad ampliada vienen investidos de unos derechos fundamentales reconocidos y protegidos por sus respectivos ordenamientos nacionales, que deben ser igualmente preservados por el derecho producto del proceso de la integración regional ${ }^{38}$.

Las modificaciones producidas en la arena internacional y el reconocimiento de nuevas libertades fundamentales obligan a reformular la conceptualización

\footnotetext{
${ }^{36}$ SAGÜÉS, Néstor P. Elementos de derecho constitucional. Buenos Aires: Astrea, 1999. v. 1. p. 30.

${ }^{37}$ Para el caso del MERCOSUR se deben destacar el Protocolo de Ushuaia sobre Compromiso Democrático en el MERCOSUR, la República de Bolivia y la República de Chile del 24 de julio de 1998, pro también los antecedentes de: la Declaración Presidencial de Las Leñas del 27 de junio de 1992 en la cual se expresaba que la plena vigencia de las instituciones democráticas es condición indispensable para la existencia y desarrollo del MERCOSUR; la Declaración Presidencial sobre Compromiso Democrático en el MERCOSUR firmada el 25 de julio de 1996 en San Luis, Argentina, y el Protocolo de Adhesión a esa declaración firmado por los presidentes de Bolivia y Chile.

${ }^{38}$ Es por ello menester recordar que según Midón: "la integración es un hecho político que se instrumenta en forma económica y jurídica, con relevantes hechos en el plano social". MIDÓN, Mario. Derecho de la integración. Buenos Aires: Rubinzal - Culzoni , 1998. p. 37. Tal como se ha sostenido en un anterior trabajo: "La integración pretende moldear aquellas precondiciones sociales y económicas nacionales con el fin de alcanzar objetivos específicos mediante el uso de ciertos instrumentos regionales". GRANATO, Leonardo; ODDONE, Nahuel. Gobiernos locales y redes asociativas: estrategias para la ciudad digital. Población y Desarrollo, San Lorenzo, a. 18, n. 36, p. 23, 2008.
} 
que estudia las relaciones entre el poder y la autoridad en el marco de un estado democrático de derecho.

El poder político, como producto o atributo esencial de la comunidad política, es la capacidad del Estado, concebida como medio para la realización del objetivo general del bien común. Es una capacidad cualitativa necesaria para mantener el orden y, por tanto, al Estado, que en el contexto antes descripto de hipermodernidad o de modernidad líquida se encuentra en una aparente situación paradójica de alta vulnerabilidad.

No hay orden social sin poder y derecho. La relación entre el poder y el derecho se materializa en una organización social y un ordenamiento jurídico específico como el Estado.

La justificación ética del ejercicio del poder estatal sobre los hombres está dada por la rectitud en el obrar con miras al fin específico de la comunidad política.

Pero también como nos recuerda Dromi no se debe olvidar que:

El poder, por definición, presupone un elemento estático, la organización, y un elemento dinámico, la actuación o acción. Actúa a través del derecho, imponiendo límites subjetivos a las garantías y libertades públicas de individuo, y límites objetivos, sobre las finalidades públicas que especifican el bien común a través de la actuación de los individuos ${ }^{39}$.

Pero el poder también se subordina al derecho, teniendo siempre como presupuesto un derecho anterior, que le impone el reconocimiento de cualidades, libertades o derechos individuales esenciales que devienen de la natural dignidad humana y que el derecho positivo no hace más que reconocer. Por ello el sistema republicano impone una relación equilibrada entre gobierno y control, las dos funciones principales del poder. Si se organiza el gobierno para

\footnotetext{
${ }^{39}$ Tal como se ha sostenido: "Si bien el ejercicio de los atributos de la autoridad, es decir de las competencias públicas, es un deber de los funcionarios, éstas son también en simultáneo derechos fundamentales de la sociedad en su conjunto. La gradación ponderada de los derechos fundamentales alcanza a los derechos individuales en sí mismos, y a los derechos del todo social". DROMI, Roberto. El derecho público en la hipermodernidad. Madrid-México D. F.: Hispania libros y servicio de publicaciones de la facultad de derecho de la Universidad Complutense, 2005. p. 41.
} 
dotarlo de autoridad, se debe instalar el control a fin de dotarlo de aptitud para resguardar la libertad ${ }^{40}$.

Los deberes del Estado se condicen con los derechos fundamentales de los ciudadanos, en tanto comprenden las competencias que la autoridad pública se encuentra obligada a ejercer en beneficio del conjunto social. A modo de ejemplo, dentro del derecho constitucional y, particularmente, dentro de las propias Constituciones se ordena conductas al gobierno en beneficio de los derechos individuales de los ciudadanos; esto acontece cuando se atribuyen constitucionalmente competencias-deberes al órgano legislativo bajo los términos "proveer", "promover", "reconocer", "garantizar" o "asegurar", entre otros.

Existen derechos fundamentales que sin esta instancia redistributiva del Estado no pueden ser ejercidos por sus destinatarios. Son derechos que le corresponden al ciudadano pero que deben pasar necesariamente por el filtro de las categorías jurídicas de las competencias públicas, para que regresen al ciudadano con fórmulas de equidad, solidaridad y transparencia; todas ellas constitutivas y estructurales al denominado "bien común".

Según Colomer Viadel:

El Gobierno se ha convertido, en el marco del Estado social y democrático de Derecho, en un órgano de especial trascendencia [...]. En efecto, en la actualidad la función del Gobierno es hoy el poder político más fuerte como consecuencia de las transformaciones que ha experimentado el Estado en los últimos tiempos ${ }^{41}$.

Por su parte, el Estado es además titular de derechos subjetivos que se manifiestan en sus actos de poder público, como forma de ejercicio de sus atribuciones. $\mathrm{Si}$ al poner en práctica tales derechos no se toman en consideración las vinculaciones entre las relaciones de causalidad y finalidad, pueden ejercerse con abuso y corrupción, con exceso o desviación, apartándose del buen origen, sentido y finalidad de dichas atribuciones.

\footnotetext{
${ }^{40}$ DROMI, Roberto. El derecho público en la hipermodernidad. Madrid-México D. F.: Hispania libros y servicio de publicaciones de la facultad de derecho de la Universidad Complutense, 2005. p. 41.

${ }^{41}$ COLOMER VIADEL, Antonio. Constitución, estado y democracia en el siglo XXI. Valencia: Editorial de la Universidad Politénica de Valencia, 2006. p. 452.
} 
Por otro lado, no sólo han cambiado el contenido y el modo de ejercicio de la autoridad, sino también -y quizá por sobre todo- los sujetos o actores que se consideran titulares o con capacidad para ejercerla. Por ejemplo, el surgimiento y difusión de los procesos de integración regional han traído como consecuencia la instauración de autoridades regionales y comunitarias que pueden asumir un carácter de tipo supranacional o intergubernamental, con múltiples atribuciones y deberes ${ }^{42}$.

También la aparición de las denominadas "unidades subnacionales" como entidades políticas intermedias, tales como las regiones, que pueden reunir zonas y gobiernos locales dentro de un mismo país o entre países vecinos, así como los nuevos roles desempeñados por los Departamentos, Estados Federados, Provincias, Metrópolis o grandes ciudades, representa la necesidad de estudiar viejos fenómenos de asociación política en su faz internacional, desde el punto de vista que su objeto es velar de modo más eficiente por el cumplimiento de los derechos subjetivos públicos ${ }^{43}$.

El fortalecimiento institucional local como parte de la descentralización puede facilitar la construcción de redes de colaboración y cooperación entre los

${ }^{42}$ Como sostuviéramos en un anterior trabajo: "El estado actual del sistema internacional parece indicar que las opciones de política económica internacional son más realizables sobre bases integradas. La integración fue y es vista como un recurso de los Estados - Nación. Hay que saber qué integrar, cómo integrarse y para qué integrarse. El qué integrar hace referencia a que sectores de la economía integrar, el cómo integrarse hace referencia a con que mecanismos integrarse o mediante cuales instituciones integrarse y el para qué nos indica con que objetivo más allá de la integración nos embarcamos en el proceso de integración pues debemos recordar que la integración no es un fin en sí mismo, sino en un medio para la consecución o realización de otros fines u objetivos, los que en la mayoría de los casos continúan enlazados con el desarrollo nacional de los países que confluyen en un proceso de integración determinado. La integración se presenta como la nueva base para la toma de decisiones para lograr el desarrollo en un mundo globalizado. Los procesos de integración implican nuevas realidades que se construyen desde una mirada regional". GRANATO, Leonardo; ODDONE, Nahuel. El sistema internacional y la integración económica regional. En: DURÁN SÁENZ, Susana, GRANATO, Leonardo; ODDONE, Nahuel (Comp.). Regionalismo y Globalización: procesos de integración comparados. Buenos Aires: Editorial Universidad Abierta Interamericana, 2008. p. 22.

${ }^{43}$ Para un enfoque teórico de este tema se sugiere: LUNA PONT, Mariana. Gestión internacional de unidades subnacionales. Hacia un encuadre teórico y conceptual. En: CALDAS, Erick; GRANATO, Leonardo (Coord.). Integración regional sudamericana, quo vadis?. Mossoró: Edición de los coordinadores, 2008. 
diferentes niveles de la administración pública, avanzando así en la democracia participativa, la descentralización de responsabilidades y competencias ${ }^{44}$.

En el estudio de la descentralización, surge como necesario analizar un principio organizacional que, si bien se encuentra plasmado en estructuras nacionales y subnacionales, parece ser que ha sido el derecho comunitario el que ha permitido su aplicación a numerosas situaciones del quehacer organizativo. Nos referimos al principio de subsidiariedad. La descentralización institucional representa la aplicación en la práctica del principio político de la subsidiariedad.

El principio de subsidiariedad es un principio considerado clave al momento de la asignación de competencias entre distintos niveles de gobierno y que cobra un significativo valor al hablar de estructuras subestatales y supraestatales.

Francis Fukuyama nos indica que el principio de subsidiariedad es aquel según el cual, en las decisiones no deben intervenir niveles de gobierno superiores a los necesarios para desempeñar una determinada función ${ }^{45}$. A nuestro entender, el principio de subsidiariedad indica la atribución de la potestad de decidir al ente más próximo al ciudadano en términos de capacidad resolutiva.

La subsidiariedad así entendida, sólo puede funcionar correctamente en conjunto con una correcta asignación de competencias y en binomio con el principio de proporcionalidad.

El principio de subsidiariedad tiene por objetivo garantizar la actuación de un específico nivel de gobierno sólo si su acción resulta realmente necesaria y aporta valor añadido diferencial a la actuación de otro nivel. Trata de acercar la toma de decisiones lo más cercana posible a los ciudadanos con la comprobación constante que la acción que se emprende esta justificada en relación con las posibilidades que se ofrecen en los otros estamentos inferiores.

El principio de proporcionalidad, complementa a éste anterior y persigue también el correcto ejercicio de las competencias por parte de un nivel de gobierno al prescribir que el contenido y la forma de acción no deberán exceder de lo necesario para obtener los objetivos fijados.

\footnotetext{
${ }^{44}$ ALBURQUERQUE, Francisco. Identidad y territorio. En: ELGUE, Mario. Globalización, desarrollo local y redes asociativas. Buenos Aires: Corregidor, 1999. p. 44.

${ }^{45}$ FUKUYAMA, Francis. La construcción del estado. Buenos Aires: Sine qua non, 2004. p. 105.
} 
Estos dos principios se relacionan con un tercer principio que es el de la eficiencia, que sostiene que realizará la actividad aquel que la haga de forma más eficiente.

En términos de eficiencia, resulta necesario autorizar a los agentes locales para que actúen en función de los conocimientos locales, evitando de esta forma todos los costes que genera el movimiento de la información que circula de arriba y abajo en las jerarquías ${ }^{46}$.

Este sistema de principios subsidiariedad-proporcionalidad-eficiencia permite que la innovación sea aceptada en un mayor nivel por las organizaciones descentralizadas ya que la capacidad decisoria se extiende por los distintos niveles de acuerdo a competencias específicas y con una mayor disponibilidad de medios a partir de las tecnologías de la información y la comunicación.

La eficiencia general del sistema debe ser complementada por la estructuración de instancias de regulación y control de las actividades que permita favorecer procesos de accountability por parte de las diferentes instancias de gobierno. En este sentido, cada sociedad ofrece las condiciones específicas, por definición siempre cambiantes, para crear las propias instancias de control que ella considere.

No debemos olvidar que:

El problema [...] reside en que simplemente no existe una teoría que proporcione unas directrices generales para lograr el nivel adecuado de capacidad decisoria en la administración pública. El mismo grado de capacidad decisoria resultaría eficaz en unas sociedades e ineficaz en otras, e incluso dentro de una misma sociedad no tendría por qué funcionar en todas las etapas ${ }^{47}$.

En este contexto, debemos tener en cuenta que la flexibilidad, como principio, debe ser la característica de todo sistema creado para dedicarse a la administración pública. La flexibilidad como principio es indicativa de la posibilidad de cambiar la programación de una actividad a medida que las situaciones de origen van cambiando. La flexibilidad es también sumamente importante ante el posible surgimiento de las denominadas "lagunas competenciales".

\footnotetext{
${ }^{46}$ FUKUYAMA, Francis. La construcción del estado. Buenos Aires: Sine qua non, 2004. p. 106-107.

${ }^{47}$ FUKUYAMA, Francis. La construcción del estado. Buenos Aires: Sine qua non, 2004. p. 114.
} 
Las mejores organizaciones suelen ser las que saben adaptarse con flexibilidad a diferentes niveles de descentralización en función de la evolución de las condiciones externas ${ }^{48}$.

En este orden de ideas, el Estado Moderno nacido en el siglo XVII resulta demasiado grande para solucionar los problemas chicos, y demasiado pequeño para enfrentar los nuevos problemas producto de la globalización del siglo XX y XXI, generando la necesidad de generar nuevas escalas de governance tanto por encima como por debajo del Estado con el objetivo de escindirse en una estrategia de multi-level governance que sólo busca generar una governance global.

El derecho público se presenta en este contexto como una suerte de remedio, jarabe o medicina de amplio espectro que tiende a cubrir los viejos y nuevos dogmas de la conducta pública, tanto en el nivel supra como en el nivel infla, sobre la lógica de la una "governance de la proximidad" ${ }^{49}$.

Por ello algunos autores entienden que el derecho público es un simultáneo para las dos aldeas:

Lo local (más propia de la Nación o de la provincia) y la global (más propia de la comunidad integrada o de la instancia internacional). Este nuevo derecho se encuentra condicionado y determinado por los datos objetivos de la nueva realidad política (Estados integrados), económica (mercados comunes) y social (culturas globales). Por ello, es imprescindible que este nuevo derecho dé respuesta a los nuevos desafíos impuestos por la contemporaneidad. Esta situación objetiva que impera en el contexto cultural mundial es determinante de las nuevas regulaciones jurídicas ordenadas desde el Estado para ser parte de la vida regional e internacional $\mathrm{y}$, a su vez, ordenadas por la sociedad global del conocimiento para ser parte de la aldea global ${ }^{50}$.

\footnotetext{
${ }^{48}$ FUKUYAMA, Francis. La construcción del estado. Buenos Aires: Sine qua non, 2004. p. 116.

${ }^{49}$ Para profundizar el concepto de "governance de la proximidad", se recomienda nuestro trabajo: GRANATO, Leonardo; ODDONE, Nahuel. Gobiernos Locales y redes asociativas: estrategias para la Ciudad Digital. En: Población y Desarrollo San Lorenzo, a. 18, n. 36, 2008.

${ }^{50}$ DROMI, Roberto. El derecho público en la hipermodernidad. Madrid-México D. F.: Hispania libros y servicio de publicaciones de la facultad de derecho de la Universidad Complutense, 2005. p. 45-46.
} 
La síntesis histórica de los tiempos del derecho público en el marco de la nueva comprensión hipermoderna o moderna líquida del poder y de las relaciones internacionales contemporáneas extiende sus efectos al fortalecimiento del orden y del bien como fuentes de legitimación y justificación del poder; el reparto y fraccionamiento de las funciones del poder como exigencia y símbolo de la libertad y de la legalidad; los nuevos diálogos entre el Estado y la sociedad civil que generan nuevos instrumentos y herramientas de organización y de la autoridad pública con el mismo objetivo de siempre de perseguir el bien común para todos los hombres de este mundo.

\section{A modo de conclusión}

En este artículo hemos pretendido identificar los ejes fundamentales de la evolución y las transformaciones experimentadas por el Estado y su organización jurídica y política a lo largo de la historia.

Las transformaciones de las instituciones que integran el sistema de derecho acompañan a los cambios que experimenta la organización del Estado producto de los cambios sufridos en la sociedad.

Si los tiempos del Estado se corresponden con los tiempos del derecho, ambos se corresponden con los tiempos de la sociedad. Los cambios del derecho son producto de los cambios del Estado y los del Estado con los cambios de la sociedad, en un proceso con características de recursividad organizacional.

Analizar la organización jurídica de la sociedad occidental, las características de la sociedad contemporánea y el diseño de las nuevas instituciones nos ha permitido extraer algunas reflexiones sobre el rol del Estado y la sociedad en las relaciones internacionales del mundo presente.

Repasar la síntesis histórica de los tiempos del derecho público en el marco de la nueva comprensión del poder y de las relaciones internacionales contemporáneas refuerza sus efectos sobre el fortalecimiento del orden y del bien común como fuentes de legitimación y justificación del poder; del reparto y fraccionamiento de las funciones del poder como exigencia y del símbolo de la libertad y la igualdad jurídica; de los renovados y fluidos diálogos entre el Estado y la 
sociedad civil que generan nuevos y amplios debates sobre el rol de la autoridad pública en la actualidad.

\section{Abstract}

This article aims to identify the main pillars of the evolution and transformation experienced by the State and its legal and political organization throughout the history until today, giving an account of the main features of contemporary society.

Key words: State. Society. Evolution. Transformation. International Relations.

\section{Referências}

ALBURQUERQUE, Francisco. Identidad y territorio. En: ELGUE, Mario. Globalización, desarrollo local y redes asociativas. Buenos Aires: Corregidor, 1999.

BAUMAN, Zygmunt. La globalización: consecuencias humanas. Buenos Aires: Fondo de Cultura Económica, 2006.

BAUMAN, Zygmunt. Modernidad líquida. Buenos Aires: Fondo de Cultura Económica, 2006.

BECK, Ulrich. ¿Qué es la globalización? falacias del globalismo, respuestas de la globalización. Barcelona: Paidós, 1997.

BERNAL-MEZA, Raúl. Argentina: la crisis del desarrollo y de su inserción internacional. São Paulo: Fundación Konrad Adenauer Stiftung, 2001. (Documentos de Análisis e Informaciones, n.1).

BERNAL-MEZA, Raúl. Sistema mundial y MERCOSUR. Buenos Aires: Universidad Nacional del Centro de la Provincia de Buenos Aires: Nuevo Hacer-Grupo Editor Latinoamericano, 2000.

BODIN, Jean. Los seis libros de la república. Madrid: Tecnos, 1997.

CALDAS, Erick y GRANATO, Leonardo (Coord.). Integración regional sudamericana. Mossoró: Edición de los coordinadores, 2008. 
COLOMER VIADEL, Antonio. Constitución, estado y democracia en el siglo XXI. Valencia: Editorial de la Universidad Politénica de Valencia, 2006.

DIEZ PICAZO, Luis María. Sistema de derechos fundamentales. Madrid: Thompson-Civitas, 2003.

DROMI, Roberto. El derecho público en la hipermodernidad. Madrid-México D. F.: Hispania libros y servicio de publicaciones de la facultad de derecho de la Universidad Complutense, 2005.

DURÁN SÁENZ, Susana; GRANATO, Leonardo; ODDONE, Nahuel (Comp.). Regionalismo y globalización: procesos de integración comparados. Buenos Aires: Editorial Universidad Abierta Interamericana, 2008.

DUROSELLE, Jean Baptiste. Tout empire périra: théorie des relationsi internationales. Paris: Aeman Collin, 1992.

ELGUE, Mario. Globalización, desarrollo local y redes asociativas. Buenos Aires: Corregidor, 1999.

FABBRINI, Sergio. Il processo d'integrazione europea: quali insegnamenti per le altre esperienze di aggregazione regionale. En: CONFERENCIA EL PROCESO DE INTEGRACIÓN EUROPEO: ENSEÑANZAS PARA OTRAS EXPERIENCIAS DE INTEGRACIÓN REGIONAL. Ponencia preparada para la conferencia... Organizada por la Universidad Abierta Interamericana y el Centro Argentino de Estudios Internacionales. Buenos Aires, 2007.

FUKUYAMA, Francis. La construcción del estado. Buenos Aires: Sine qua non, 2004.

GOLDSCHMIDT, Werner. El principio supremo de justicia. Buenos Aires: Editorial de la Universidad de Belgrano, 1984.

GRANATO, Leonardo; ODDONE, Nahuel. Gobiernos locales y redes asociativas: estrategias para la ciudad digital. Población y Desarrollo, San Lorenzo, a. 18, n. 36, 2008.

GRANATO, Leonardo; ODDONE, Nahuel. En: sistema internacional y la integración económica regional. En: DURÁN SÁENZ, Susana, GRANATO, Leonardo; ODDONE, Nahuel (Comp.). Regionalismo y globalización: procesos de integración comparados. Buenos Aires: Editorial Universidad Abierta Interamericana, 2008. 
HUBEÑÁK, Florencio. Formación de la cultura occidental. Buenos Aires: Editorial Ciudad Argentina, 1999.

JARAUTA, Francisco. Presentación. Foro de la mundialización: después del 11 de septiembre. Murcia: Fundación CajaMurcia, 2003.

KRIPPENDORFF, Ekkhart. Las relaciones internacionales como ciencia. México D. F.: Fondo de Cultura Económica, 1993.

LIPOVETZKY, Gilles-Charles-Sébastien. Les temps hypermodernes. Paris: Grasset, 2004.

LUNA PONT, Mariana. Gestión internacional de unidades subnacionales. Hacia un encuadre teórico y conceptual. En: CALDAS, Erick; GRANATO, Leonardo (Coord.). Integración regional sudamericana, quo vadis?. Mossoró: Edición de los coordinadores, 2008.

MIDÓN, Mario. Derecho de la integración. Buenos Aires: Rubinzal - Culzoni , 1998.

ODDONE, Nahuel; GRANATO, Leonardo. La globalización como proceso e ideología: las desigualdades se acrecientan. Revista Debates Latinoamericanos, Buenos Aires, a. 2, n. 3, 2004.

ODDONE, Nahuel. La red de mercociudades: globalización, integración regional y desarrollo local. Valencia: Instituto de Iberoámerica y el Mediterráneo de la Universidad Politécnica de Valencia, 2008.

PEREIRA CASTANARES, Juan Carlos. Los orígenes de la guerra fría. Madrid: Arco, 1997.

PÉREZ SERRANO, Julio. Globalización y pensamiento único. En: ENCUENTRO DE FIN DE SIGLO. UTOPÍAS, REALIDADES Y PROYECTOS. Ponencia presentada en el encuentro... Salta: Universidad Nacional de Salta, 2001.

RENOUVIN, Pierre; DUROSELLE, Jean Baptiste. Introducción a la historia de las relaciones internacionales. México D. F.: Fondo de Cultura Económica, 2000.

ROBERTSON, Ronald; WHITE, Kathleen. La glocalizzazione rivisitata ed elaborata. En: SEDDA, Franciscu. (Comp.). Glocal: sul presente a venire. Roma: Luca Sosella, 2004.

SAGÜÉS, Néstor P. Elementos de derecho constitucional. Buenos Aires: Astrea, 1999. v. 1. 
SASSEN, Saskia. Una sociología de la globalización. Buenos Aires: Katz, 2007.

SPRUYT, Hendrix. The sovereign state and its competitors. Princeton: Princeton University Press, 1994.

WALLERSTEIN, Immanuel. El moderno sistema mundial: la agricultura capitalista y los orígenes de la economía mundo europea en el siglo XVI. México: Siglo XXI, 1991.

TUCÍDIDES. Historia de la guerra del peloponeso. México D. F.: Porrúa, 1989. 